\title{
Endovascular Debulking in Therapy of Occluded Lower Limb Bypass
}

\section{Miroslav Bulvas*}

Division of Interventional Angiology, Charles University, Czech Republic

*Corresponding author: Miroslav Bulvas, Division of Interventional Angiology, Department of Surgery, Kings Vineyards Hospital, Third Medical School, Charles University, , Czech Republic, Email: miroslav.bulvas@fnkv.cz
Received Date: June 18, 2019

Published Date: June 21, 2019

\section{Mini Review}
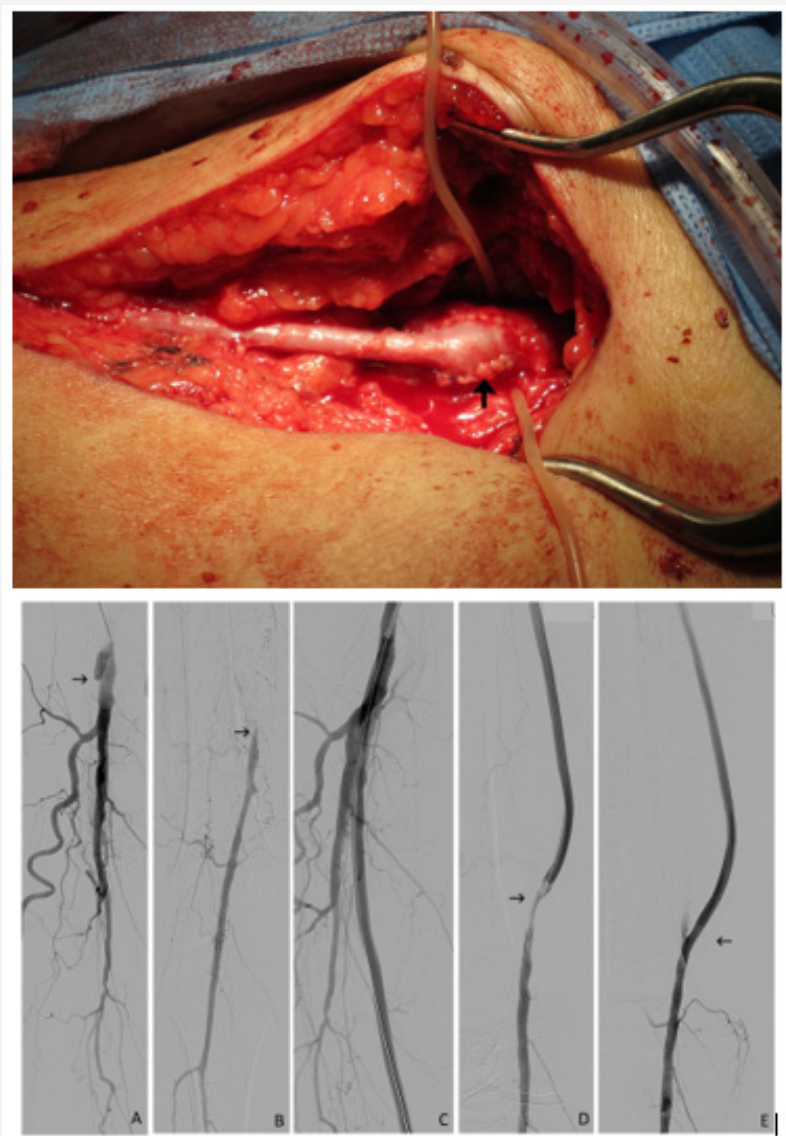

Figure 1: 71-year-old man with subacute, right lower limb ischemia, category Rutherford 3, prosthetic proximal femoropopliteal (FP) bypass thrombosis.

(A) Occlusion of prosthetic FP bypass at its origin (arrow). (B) The popliteal artery (PA) (arrow) is filled via collaterals. (C) Angiogram after bypass recanalization with the Rotarex. (D) Residual stenosis at the distal anastomosis (arrow). (E) Final angiogram after balloon angioplasty (PTA) and stenting (arrow).

The goal of surgical and/or endovascular therapy in patients with lower limb ischemia is the elimination of return or progression of serious and threatening ischemic symptoms (rest pain, ischemic ulcers or gangrene) [1-3]. Thus, bypass occlusion can be associated with renewed acute or critical ischemia and endangered lower extremity. Early (> 30 days) graft failure rate $6.3 \%$ was reported 
in the study that collected 9217 bypass procedures [4] with higher frequency in preceding emergency and re-operative procedures (8.2\%). Typically, it can be ascribed to technical factors (kinking or twisting of the graft, technical anastomotic problems. inadequate runoff, clamp injury, retained valves,) and prothrombotic state [5]. Intermediate graft failure (from 30 days to 18 months) is commonly associated with my intimal hyperplasia formation at the sites of anastomoses or valves (venous bypass grafts). Late graft failure is largely caused by the progression of atherosclerosis in the outflow or inflow vessels Figures 1 \& 6. Excellent and long-lasting results (5-year primary patency rate $85-88 \%$ ) can be expected with aortoiliac reconstruction at low risk patients. Acute thrombosis of an aortofemoral graft limb occurs in about $2 \%$ of patients during early perioperative period [6]. Primary patency rates $87-100 \%$ (1 month), 69-86\% (1 year) and 51-72\% (5 years) were reported [7] in femoropopliteal bypasses with better results for suprageniculate and autovenous saphenous grafts.

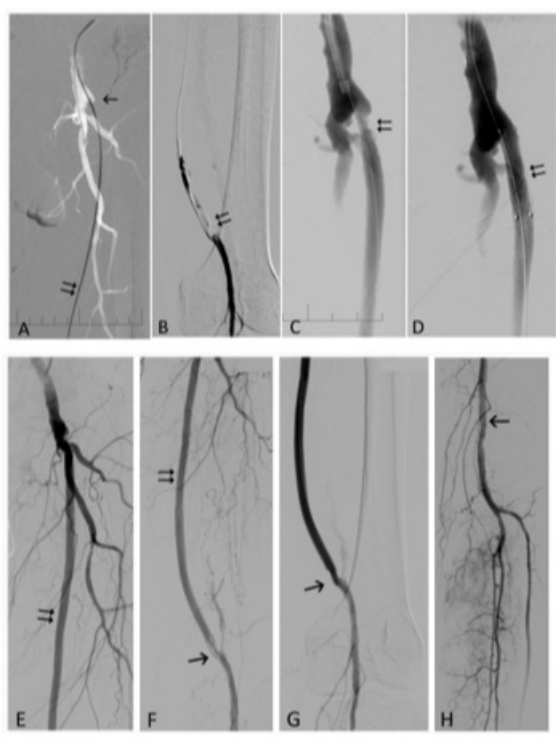

Figure 2: 73-year-old man with acute, left lower limb ischemia Ila and proximal, prosthetic FP bypass thrombosis.

(A) Occlusion of prosthetic FP bypass at its origin (arrow). Thrombus penetrated with guidewire (double arrow). (B) Selective angiogram: distal anastomosis (double arrow). C) Residual stenosis at the distal anastomosis (arrow) after the Rotarex debulking. (D) Proximal stenosis after stenting (double arrow). (E) Patent bypass after debulking. (F) Residual stenosis: distal anastomosis (arrow). (G) Distal anastomosis after PTA. (H) PA (arrow) and tibial vessels.
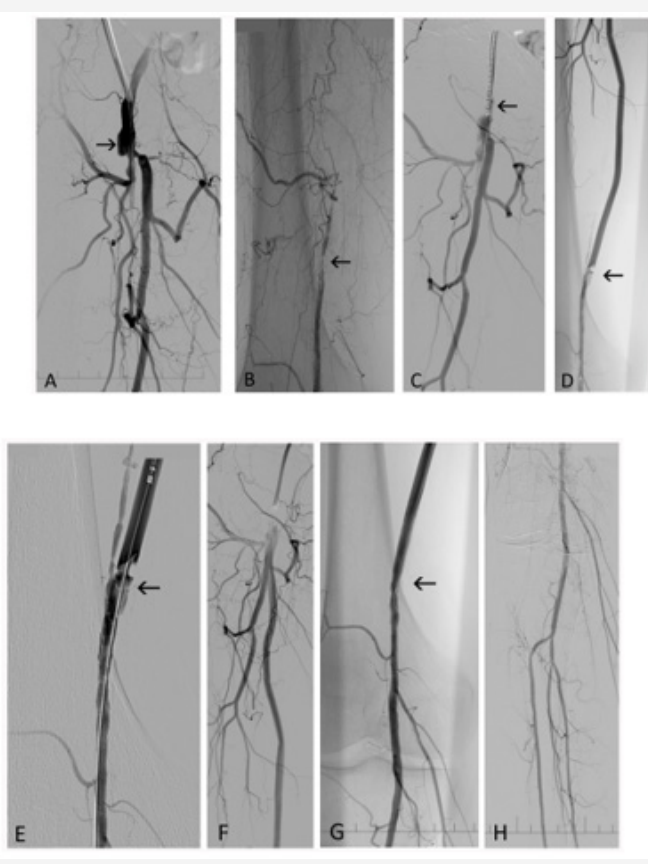

Figure 3: 61-year-old man with subacute ischemia of left lower limb, category Rutherford 4, proximal, prosthetic FP bypass thrombosis. (A) Occluded FP prosthetic bypass Insertion (arrow), stenosis of deep femoral artery (DFA). (B) PA filled via collaterals: distal anastomosis labeled by arrow. (C) Rotarex (arrow) ready for debulking. (D) $+(E)$ Distal anastomosis after bypass debulking with the Rotarex (arrow). (F) Distal anastomosis. (G) Distal anastomosis (arrow) after PTA and stenting. (H) Tibial vessels. 

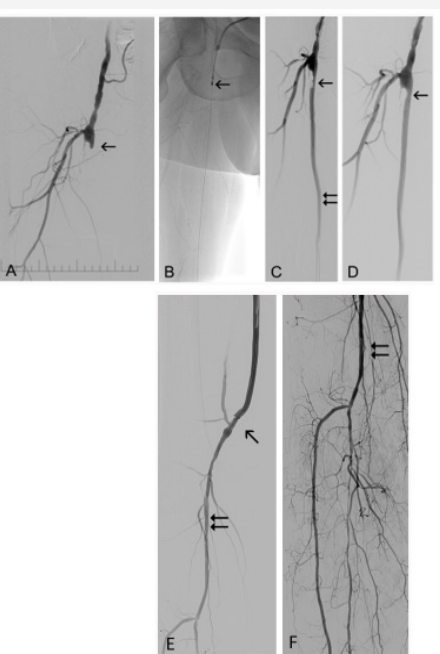

Figure 4: 65-year-old man with acute ischemia Ila, proximal, prosthetic FP bypass thrombosis.

(A) Prosthetic proximal FP bypass origin (arrow), (B) Rotarex catheter (arrow) introduced from antegrade approach. (C) Recanalized bypass (double arrow) with residual stenosis (arrow). (D) Stenosis (arrow) after adjuncive PTA. (E) Distal anastomosis (arrow) after PTA and popliteal artery (double arrow). (F) Popliteal artery (double arrow) and intrahospital vessels at the end of intervention.
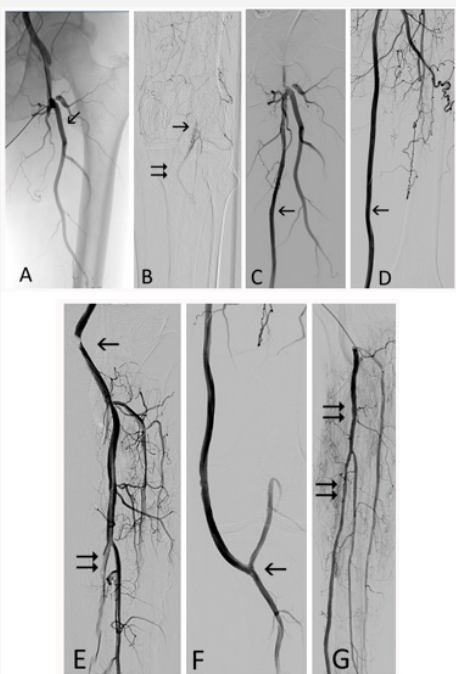

Figure 5: 85-year-old man with acute ischemia Ilb of left lower limb and thrombosis of prosthetic, distal FP bypass.

(A) Occluded distal FP bypass at its proximal insertion, patent DFA (arrow). (B) Poplitel artery (arrow) and distal anastomosis (double arrow). $(C)+(D)$ Patent bypass (arrow) after Rotarex debulking. (E) Residual thrombi in tibioperoneal trunk and posterior tibial artery (double arrow), residual stenosis in distal anastomosis. (F) Distal anastomosis (arrow) after debulking and PTA. (G) Selective angiography of tibioperoneal trunk and posterior tibial artery (double arrows) after clot removal by percutaneous aspiration thromboembolectomy (PAT).

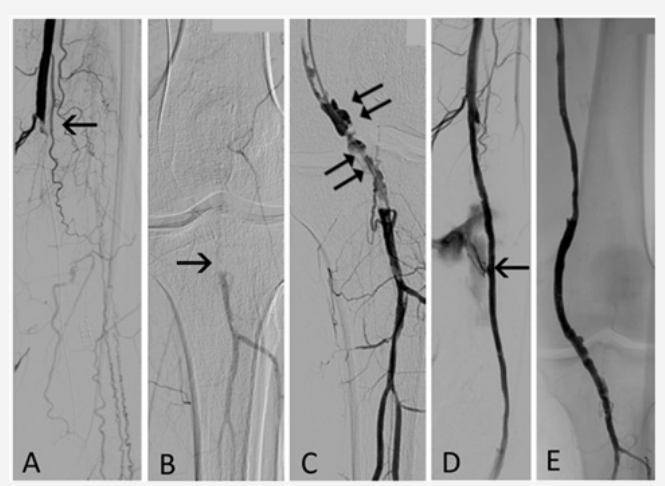

Figure 6: 55 -year-old man with acute ischemia lla and thrombosis of distal venous FP bypass. Proximal anastomosis is located in superficial femoral artery.

(A) Arrow depicts distal anastomosis site. (B) Arrow depicts distal anastomosis of occluded bypass. (C) Selective angiography of distal anastomosis (double arrows) before recanalization. (D) Angiogram after mechanical debulking. Extravasation (arrow) occured after adjunctive PTA and was excluded with stentgraft. (E) Final angiogram of recanalized bypass. 
Patients who have undergone placement of lower limb bypass grafts are followed up with periodic evaluations that record return or progression of ischemic symptoms. Therefore, hemodynamic deterioration caused by progression of proximal or distal atherosclerosis and/or intimal hyperplasia can be detected before thrombosis and occlusion develop. In those cases, preventive balloon angioplasty, stenting or percutaneous atherectomy are used to assist the primary patency.

Surgical treatment of acutely thrombosed vein graft is usually associated with thrombectomy, thrombolysis and subsequent repair of the defects responsible for graft failure. Unfortunately, only $23 \%$ of vein grafts remained patent 3 years after successful thrombolysis and revision $[5,8]$. For intermediate to late vein graft failure, a new surgical reconstruction is recommended in patients with threatened extremity. Nevertheless, advanced comorbidities and anatomy can preclude major reoperation. Furthermore, it can be difficult to find sufficient vein for reoperation in patients with occluded prosthetic grafts. For secondary bypass grafts, $25 \%$ primary patency (prosthetic) and 43\% (autogenous vein) were reported [5] five years after reoperation.

Surgical or thrombolytic limitation is the driving force for usage of the modalities with purely endovascular, mechanical approach in the management of occluded bypasses. For the Rotarex catheter, $98-100 \%$ technical success was reported in the series with acute and subacute occlusions of femorpopliteal bypasses $[9,10]$. Lichtenberg et al. managed 22 patients with venous (12) and prosthetic (10) occluded by passes without major complication, death or reintervention during 6-month follow-up. Wissgott et al. reported $98 \%$ technical success in 42 patients with $81 \%$ of venous bypasses, $4.8 \%$ of complications (no amputation, no death) and $66 \%$ of 12 -month primary patency [11]. Reported lower primary success $(78 \%)$ in 9 patients with occluded femoropopliteal bypasses compared to 91 cases of infraaortic occlusions. Mixed series of 316 patients [12] with acute and subacute lower limb ischemia (72 femoropopliteal bypass occlusions) reached $100 \%$ technical success at the level of target vessels with only a minor complication (8\%) associated with debulking therapy. The overall therapeutic success was negatively influenced by infrapopliteal artery status and the low potential for effective endovascular and surgical treatment in this runoff area [12].

\section{Conclusion}

Mechanical debulking with the Rotarex catheter can be used as an initial treatment in patients with occluded lower limb bypasses especially in those, at high surgical risk or predisposed to bleeding.

\section{Acknowledgement}

None.

\section{Conflict of Interest}

M.B. worked as a proctor for Straub Medical AG.

\section{References}

1. Gerhard Herman, Gornik HL, Barrett C, Neal R Barshes, Matthew A Corriere, et al. (2017) 2016 AHA/ACC Guideline on the management of patients with lower extremity peripheral artery disease: executive summary. A report of the American College of Cardiology/American Heart Association Task Force on Clinical Practice Guidelines. Circulation 135: e686-e725.

2. Norgren L, Hiatt WR, Dormandy JA, Nehler MR, Harris KA, et al. (2007) Inter-society consensus for the management of peripheral arterial disease (TASC II). Eur J Vasc Endovasc Surg 45 Suppl S: S5-67.

3. Aboyans V, Ricco JB, Bartelink MEL, Björck M, Brodmann M, et al. (2018) 2017 ESC Guidelines on the Diagnosis and Treatment of Peripheral Arterial Diseases, in collaboration with the European Society for Vascular Surgery (ESVS). Eur Heart J 39: 763-816.

4. Lancaster RT, Conrad MF, Patel VI, Cambria RP, LaMuraglia GM, et al. (2012) Predictors of early graft failure after infrainguinal bypass surgery: a risk-adjusted analysis from NSQIP. Eur J Vasc Endovasc Surg 43(5): 549-555.

5. Belkin M (2009) Secondary bypass after infrainguinal bypass graft failure. Semin Vasc Surg 22: 234-239.

6. Chiu KW, Davies RS, Nightingale PG, Bradbury AW, Adam DJ, et al. (2010) Review of direct anatomical surgical management of atherosclerotic aorto-iliac occlusive disease. Eur J Vasc Endovasc Surg 39: 460-471.

7. Ziegler KR, Muto A, Eghbalieh SDD, Dardik A (2011) Basic data related to surgical infrainguinal revascularization procedures: a twenty year update. Ann Vasc Surg 25: 413-422.

8. Belkin M, Donaldson MC, Whittemore AD, PolakJF, Grassi CJ, et al. (1990) Observations on the use of thrombolytic agents for thrombotic occlusion of infrainguinal vein grafts. J Vasc Surg 11: 289-296.

9. Lichtenberg M, Käunicke M, Hailer B (2012) Percutaneous mechanical thrombectomy for treatment of acute femoropopliteal bypass occlusion. Vascular Health and Risk Management 8: 283-289.

10. Wissgott C, Kamusella P, Andresen R (2013) Recanalization of acute and subacute venous and synthetic bypass-graft occlusions with mechanical rotational catheter. Cardiovasc Intervent Radiol 36: 936-942.

11.Zeller T, Frank U, Bürgelin K, Müller C, Flügel P, et al. (2003) Early experience with a rotational thrombectomy device for treatment of acute and subacute infra-aortic arterial occlusions. J Endovasc Ther 10: 322-331.

12. Bulvas M, Sommerová Z, Vaněk I, Weiss J (2019) Prospective single-arm trial of debulking as initial therapy in patients with acute and subacute lower limb ischemia: one-year outcomes. J Endovasc Ther 26(3): 291301. 